\title{
Maternity Care Services Utilization and Factors Associated with Institutional Delivery Among Postpartum Women in Dabat Demographic and Health Survey Site, Northwest Ethiopia: A Community Based Baseline Survey for $\mathrm{MNCH}$ Surveillance
}

Abebaw Addis Gelagay

University of Gondar

Abebaw Gebeyehu Worku

University of Gondar

Debrework Tesgera Bashah

University of Gondar

Nigusie Birhan Tebeje University of Gondar

Mignote Hailu Gebrie University of Gondar

Hedija Yenus Yeshita University of Gondar

Endeshaw Adimasu Cherkose

University of Gondar

Ayenew Molla Lakew ( $\sim$ mayenew15@gmail.com )

University of Gondar

Berihun Assefa Dachew

University of Gondar

Amare Tariku

University of Gondar

Aysheshim Kassahun Belew

University of Gondar

Birhanu Abera Ayana

University of Gondar

Gashaw Andargie Bikes

University of Gondar 


\section{Research Article}

Keywords: Dabat Demographic and Health survey, Antenatal care, Institutional delivery, and Postnatal care, Ethiopia

Posted Date: December 9th, 2021

DOI: https://doi.org/10.21203/rs.3.rs-1046903/v1

License: (c) (i) This work is licensed under a Creative Commons Attribution 4.0 International License.

Read Full License 


\section{Abstract \\ Background}

Maternal continuum of care is identified to have a greatest impact on maternal and child survival. However, there is a wide variation in maternal health services utilization from place to place in Ethiopia. Therefore, knowing antenatal care, labor and delivery, and postnatal care uptake has paramount importance to take interventions.

\section{Methods}

A community-based cross-sectional survey was conducted among 1626 postpartum women. Descriptive statistics were done to characterize the study population and utilization of antenatal care, institutional delivery, and postnatal care services. Logistic regression analysis was employed to identify factors associated with institutional delivery.

\section{Results}

Nearly eighty percent, $(79.7 \%, 95 \% \mathrm{Cl}: 77.7,81.6)$, of women attended at least one antenatal care visit at any health facility. However, only less than one third (31.4\%) used all the recommended antenatal care (ANC). About half, 820 (49.2\%: 95\% Cl: 46.7, 51.8) women delivered their child in health institution. About half, 822 (50.6\%, 95\% Cl: $48.2,52.9)$ of postpartum women who participated in this study had at least one postnatal care (PNC) visit at health facilities. Being urban resident ( $A O R=8.18,95 \% \mathrm{Cl}: 4.69,14.26)$ ), respondents of higher educational status (AOR=4.99,95\%Cl: 2.51,9.90), being Orthodox Christian (AOR= $2.35,95 \% \mathrm{Cl}: 1.15,4.79)$, getting TT vaccination during pregnancy (AOR=1.54, 95\% Cl: 1.06, 2.23), and antenatal care utilization ( $\mathrm{AOR}=2.97,95 \% \mathrm{Cl}: 2.06,4.27)$ were predictors for health facility/institutional delivery.

\section{Conclusions}

Though a significant proportion of the study participants initiated antenatal care, utilization of all the recommended antenatal care visits, facility delivery, and postnatal care services were low. Health professionals need to use the first antenatal care visit as a golden opportunity to attract and maintain pregnant women for the subsequent maternal health care services.

\section{Background}

Pregnancy and childbirth is a potentially risky and fatal experience for many of women in developing countries. In spite of evidences which shows that motherhood can be safer for all women by following a set of life-saving strategies, maternal death is still unacceptably high. Globally, about 295,000 women 
died as a result of pregnancy-related complications in 2017. Among which sub-Saharan Africa accounted about two-thirds $(196,000)$. The majority $(75 \%)$ of these deaths are due to direct obstetric conditions like hemorrhage, puerperal sepsis, pre-eclampsia, eclampsia and obstructed labour [2, 3].

Evidence has shown a connection between having skilled care during childbirth and reduction in maternal mortality [4]. The risk of death from complications related to pregnancy and childbirth over the course of a woman's lifetime in a developing country is high compared with the industrialized world, where there is sufficient skilled birth attendance [5]. The key for improving maternal health and reducing maternal mortality by preventing and managing complications. Hence, all women need access to high quality care during pregnancy, labor and delivery, and postnatal period [3].

Major causes of maternal deaths in Ethiopia are similar to most developing countries, such as haemorrhage, obstructed labour, hypertensive disorder of pregnancy, pueriperial sepsis, and abortion[6]. Most of the causes of maternal morbidity and mortality are preventable and treatable with appropriate interventions such as uptake of the maternal continuum of care that are prenatal, natal and postnatal care [7]. Provision of health promotion, screening and diagnosis, and disease prevention are dimensions of Antenatal care (ANC) services. Though World Health Organization (WHO) revised the ANC guideline and suggest 8 ANC contacts, Ethiopia is implementing the focused antenatal care schedule which notes a pregnant women should have a minimum of four antenatal care follow up [8]. Initiation of prenatal care is a golden opportunity for health professionals to provide ANC and counseling services that make pregnant women continue a continuum of the four recommended ANC, institutional delivery, and postnatal care [8]. Skilled birth attendance and four visits of postnatal care are identified as a prioritized service to avert preventable maternal deaths and morbidities. However, the magnitude of ANC, skilled delivery and postnatal service utilization varies from place to place in Ethiopia and across countries. For example, Institutional delivery was as low as $12.3 \%$ in a study conducted in Munisa district (Arisi zone, Ethiopia)[9]. Similarly, ANC4+ and PNC uptake were as low as $29.8 \%$, and $34.8 \%$ respectively in a study conducted in Dembecha [10]. In contrast, ANC, institutional delivery, and postnatal care uptake were as high as 97.6\%, 96.2\%, and 65.6\% respectively in a study conducted in Addis Ababa, Ethiopia [11]. Hence, knowing the maternal health services utilization status has paramount importance to design strategies and interventions regionally and/or locally. Additionally, this is a census study aimed to have a baseline information on maternity service utilization for the longitudinal study on maternal child health in Dabat Demographic and Health Survey site. So, the objective of the study was to assess utilization of antenatal care, institutional delivery and Postnatal services among women who had child age less than one year in Dabat Demographic and Health survey (DHS) site.

\section{Methods}

\section{Study area, population, and design}

A Community based cross-sectional survey was conducted to determine antenatal care, institutional delivery, and postnatal service utilization in Dabat demographic and health research site. The centre is 
among the six Health and Demographic Surveillance Systems in Ethiopia. According to the Central Statistics Agency (CSA) report of Ethiopia, the district has an estimated population of 145,458 people in 27 rural and 3 urban Kebeles (the smallest administrative units in the country). The research centre includes 13 Kebeles (9 rural and 4 urban) representing each agro-ecological zones of the district, and there are 5 health centers and 29 health posts in the district. The study population included women of reproductive age (15-49) years who were pregnant identified by house to house survey.

\section{Sample size and sampling technique}

The sample size was determined using single population proportion formula considering antenatal care coverage and facility delivery from the 2016 Ethiopian Demographic and Health Survey report. In the report, the proportion of ANC and facility delivery in Amhara Region were $67 \%$ and $27 \%$ respectively [12]. Considering the standard normal distribution, the Z-score at $95 \%$ confidence level is 1.94 ; power of $80 \%$ and $4 \%$ margin of error, the final estimated sample size with a $10 \%$ for non-response rate were 584 and 520 for antenatal care and skilled delivery respectively. But, since the study was nested in the Dabat Demographic and Health Surveillance (DHS) data and this baseline survey was the base for the Maternal and Neonatal and Child Health ( $\mathrm{MNCH}$ ) surveillance, a census of pregnant and postpartum women was done. Hence, a total of 1626 postpartum women who had children aged less than one year were included from urban and rural Kebeles of Dabat DHS.

\section{Data Collection tools and procedures}

Questionnaire was developed in English from related literature and translated to Amharic, the local language of the area and then translated back to English for consistency and analysis. A structured and pretested questionnaire was used to collect the data. Supervisors and enumerators from the research center were recruited and trained for five days on the study objectives, briefed on the content of the questionnaire and procedure prior to fieldwork. Participants' informed consent was obtained and privacy and confidentiality were maintained.

\section{Data management and analysis}

All questionnaires were checked for consistency and completeness. The data were entered in to computer using Epi-data version 3.1 and exported to STATA version 14. Data were cleaned and coded first.

Descriptive statistics were done to see the frequency and proportion of socio-demographic characteristics of the study participants, ANC care utilization, institutional delivery and postnatal care utilization. Logistic regression analysis was done to identify determinants of institutional delivery.

\section{Results}

\section{Socio-demographic characteristics of women}

The mean (SD) age of the respondents was $31.5( \pm 5.61)$ years. Nearly one third of the women are in the age range of 35-39 years. The greater proportion of mothers were rural residents (85.9\%), orthodox 
Christian religion followers (96.2\%) and Amhara by ethnicity (92.2\%). Among the participants, $69.74 \%$ were in educational category of unable to read and write, and $3.2 \%$ were with educational level of preparatory and above. The majority $97.17 \%$ were married while $1.17 \%$ were divorced (Table 1 ). 
Table 1

Demographic characteristics and ANC uptake among postpartum women at Dabat Demographic and Health Survey site, $2016(\mathrm{~N}=1626)$

\begin{tabular}{|c|c|c|c|}
\hline Variables & Category & Frequency & Percentage \\
\hline \multirow[t]{7}{*}{ Age } & $15-19$ & 47 & 2.89 \\
\hline & $20-24$ & 263 & 16.17 \\
\hline & $25-29$ & 366 & 22.51 \\
\hline & $30-34$ & 236 & 14.51 \\
\hline & $35-39$ & 533 & 32.78 \\
\hline & $40-44$ & 135 & 8.3 \\
\hline & $45-49$ & 46 & 2.83 \\
\hline \multirow[t]{2}{*}{ Residence } & Urban & 229 & 14.08 \\
\hline & Rural & 1397 & 85.92 \\
\hline \multirow[t]{3}{*}{ Religion } & Orthodox Christian & 1565 & 96.25 \\
\hline & Muslim & 55 & 3.38 \\
\hline & Protestant & 6 & 0.37 \\
\hline \multirow[t]{2}{*}{ Ethnicity } & Amhara & 1500 & 92.25 \\
\hline & Others & 126 & 7.75 \\
\hline \multirow[t]{6}{*}{ Educational status } & Unable to read and write & 1134 & 69.74 \\
\hline & Able to read and write & 88 & 5.41 \\
\hline & Elementary (1-6) & 208 & 12.79 \\
\hline & Junior 7-8 & 53 & 3.26 \\
\hline & High school(9-10) & 91 & 5.6 \\
\hline & $\geq$ preparatory $(11+)$ & 52 & 3.2 \\
\hline \multirow[t]{4}{*}{ Marital status } & Married & 1590 & 97.7 \\
\hline & Single & 13 & 0.88 \\
\hline & Divorced/separated & 19 & 1.18 \\
\hline & Widowed & 4 & 0.24 \\
\hline
\end{tabular}


Nearly $80 \%$ of $(79.7 \%, 95 \% \mathrm{Cl}: 77.7,81.6)$ of women attended at least one antenatal care visit at any health facility (including health post where there is no laboratory services) for the indexed child. Among these, majority, $1159(71.3 \%)$ attended at health center while $114(7 \%)$ and $23(1.4 \%)$ had attended at health post and Hospital/private clinic respectively. Hence, nearly three-fourth, 1182 (72.7\%, 95\% Cl: 70.4, 74.8), of the study participants had used at least one Antenatal care (ANC) visit from health facilities where there are laboratory services and skilled health professionals. Among the study participants, slightly less than a third, $(31.4 \% \%, 95 \% \mathrm{Cl}$ : 29.2, 33.7), had completed the recommended (ANC4+) follow up visit (Figure 1).

\section{Component of ANC services women obtained}

During ANC follow-up, pregnant women got a variety of services. Nearly three-fourth, $1166(71.7 \%)$, of respondents took at least one dose of tetanus toxoid (TT) vaccination and 655(40.3\%) had taken two doses of TT vaccination during pregnancy of the indexed child. Slightly greater than half, $698(53.86 \%)$ and majority, 1,054 (81.33\%), women had been counseled about danger signs and place of delivery, respectively (Table 2 ). 
Table 2

Components of ANC obtained among postpartum women at Dabat Demographic and Health Survey site, 2016

\begin{tabular}{|c|c|c|}
\hline Variables & Frequency & Percentages \\
\hline \multicolumn{3}{|c|}{ TT vaccination during pregnancy $(n=1626)$} \\
\hline Two doses & 655 & 40.30 \\
\hline Single Dose & 511 & 31.40 \\
\hline Not taken at all & 460 & 28.30 \\
\hline \multicolumn{3}{|c|}{ HIV counseling services $(n=1296)$} \\
\hline Yes & 858 & 66.2 \\
\hline No & 438 & 33.8 \\
\hline \multicolumn{3}{|c|}{ HIV testing ( $n=1296)$} \\
\hline Yes & 238 & 18.36 \\
\hline No & 1058 & 81.64 \\
\hline \multicolumn{3}{|c|}{ Advice on danger sign on pregnancy and birth preparedness } \\
\hline Yes & 698 & 53.86 \\
\hline No & 598 & 46.14 \\
\hline \multicolumn{3}{|c|}{ Advice on place of delivery } \\
\hline Yes & 1,054 & 81.33 \\
\hline No & 242 & 18.67 \\
\hline \multicolumn{3}{|c|}{ Taking Iron/folic acid } \\
\hline Yes & 1,004 & 77.47 \\
\hline No & 292 & 23.53 \\
\hline \multicolumn{3}{|c|}{ Advice on family planning } \\
\hline Yes & 304 & 23.46 \\
\hline No & 992 & 76.54 \\
\hline \multicolumn{3}{|c|}{ Advice on breast feeding } \\
\hline Yes & 223 & 17.21 \\
\hline No & 1,073 & 82.79 \\
\hline
\end{tabular}


Among the study participants, about half, 820 (49.2\%: 95\% Cl: 46.7, 51.8), delivered their child in health facility (Figure 2). Family members were the main, 659 (79.8\%) birth attendants for women who had home delivery. Majority, 1547 (95.1\%), of the women had a spontaneous vaginal delivery (SVD). Delivery by cesarean section (C/S) and assisted delivery were $21(1.3 \%)$ and $58(3.6 \%)$, respectively.

\section{Postnatal Care Utilization}

About half, $822(50.6 \%, 95 \% \mathrm{Cl}: 48.2,52.9)$ of postpartum women who participated in this study had at least one postnatal care (PNC) visit at health facilities. Among these, the majority (50.1\%, 95\% Cl: 47.7, 52.4) had initiated within the first week of the postpartum period (Figure 3).

\section{Factors associated with Institutional delivery}

Bivariable and multivariable logistic regression analyses were used to identify factors associated with institutional delivery. Thus, residence, respondents' educational status, religion, number of TT vaccination taken during pregnancy for indexed child, and ANC utilization at the recommended place were the factors associated with institutional delivery.

Institutional delivery was eight $(\mathrm{AOR}=8.18,95 \% \mathrm{Cl}: 4.69,14.26)$ times higher among urban residents and five times (AOR=4.99, 95\% Cl: 2.51, 9.90) higher among women who completed high school and above education. The odds of giving birth at health facility was two times higher ( $\mathrm{AOR}=2.35,95 \% \mathrm{Cl}: 1.15,4.79)$ in Muslim religion followers than Orthodox Christian. Postpartum women who took two doses of TT vaccination during pregnancy for the indexed child were $54 \%(A O R=1.54,95 \% \mathrm{Cl}: 1.06,2.23)$ higher to give birth at health facility than those who did not take the vaccination. Similarly, women who used ANC at recommended place were three times ( $\mathrm{AOR}=2.97,95 \% \mathrm{Cl}: 2.06,4.27)$ higher to deliver at health facility than those who had no ANC follow up (Table 3 ). 
Table 3

Bivariable and Multivariable logistic regression for institutional delivery among postpartum women at Dabat Demographic and Health Survey site, 2016

\begin{tabular}{|c|c|c|c|c|}
\hline \multirow[t]{2}{*}{ Variables } & \multicolumn{2}{|c|}{$\begin{array}{l}\text { Institutional } \\
\text { Delivery }\end{array}$} & \multirow[t]{2}{*}{ COR with $95 \% \mathrm{Cl}$} & \multirow[t]{2}{*}{ AOR with $95 \% \mathrm{Cl}$} \\
\hline & Yes & No & & \\
\hline \multicolumn{5}{|l|}{ Residence } \\
\hline Urban & 213 & 16 & $\begin{array}{l}18.37(10.93 \\
30.87)^{\star \star}\end{array}$ & $\begin{array}{l}8.18(4.69 \\
14.26)^{\star \star}\end{array}$ \\
\hline Rural & 587 & 810 & 1 & \\
\hline \multicolumn{5}{|l|}{ Educational Status } \\
\hline No Formal class & 518 & 704 & 1 & 1 \\
\hline Elementary school (Grade 1-6) & 117 & 91 & $1.75(1.29,2.35)^{\star \star}$ & $1.18(0.84,1.65)$ \\
\hline Junior school (Grade 7-8) & 33 & 20 & $2.24(1.27,3.95)^{\star}$ & $1.19(0.63,2.24)$ \\
\hline High school and above (Grade 9+) & 132 & 11 & $\begin{array}{l}\text { 16.31 (8.73 } \\
30.48)^{\star \star}\end{array}$ & $\begin{array}{l}4.99(2.51 \\
9.90)^{\star \star}\end{array}$ \\
\hline \multicolumn{5}{|l|}{ Religion } \\
\hline Orthodox Christian & 751 & 814 & 1 & 1 \\
\hline Muslim & 49 & 12 & $4.43(2.34,8.38)^{\star \star}$ & $2.35(1.15,4.79)$ * \\
\hline \multicolumn{5}{|l|}{ Ethnicity } \\
\hline Amhara & 746 & 754 & 1 & 1 \\
\hline Others@ & 54 & 72 & $0.76(0.53,1.09)$ & $0.94(0.63,1.41)$ \\
\hline \multicolumn{5}{|l|}{ Number of TT vaccination } \\
\hline Not vaccinated at all & 135 & 325 & 1 & 1 \\
\hline One times & 276 & 235 & $2.83(2.17,3.69)^{\star \star}$ & $1.23(0.84,1.79)$ \\
\hline Two times & 389 & 266 & $3.52(2.73,4.54)^{\star \star}$ & $1.54(1.06,2.23)^{\star}$ \\
\hline \multicolumn{5}{|l|}{$\begin{array}{l}\text { ANC Utilization at recommended } \\
\text { place }\end{array}$} \\
\hline Yes & 701 & 481 & $5.08(3.95,6.53) \star \star$ & $\begin{array}{l}2.97(2.06 \\
4.27)^{\star \star}\end{array}$ \\
\hline No & 99 & 345 & 1 & 1 \\
\hline
\end{tabular}

$\varrho^{@}$ Tigrie and Kimant; * Significant at P-value less than 0.05; **Significant at P-value less than 0.001 


\begin{tabular}{|llllll|}
\hline Variables & \multicolumn{2}{l}{$\begin{array}{l}\text { Institutional } \\
\text { Delivery }\end{array}$} & & COR with 95\% Cl & AOR with 95\% Cl \\
\cline { 2 - 5 } & Yes & No & & \\
\hline Partner HIV test & 60 & 54 & $1.159(0.79,1.69)$ & $0.89(0.59,1.35)$ \\
\hline Yes & 740 & 772 & 1 & 1 \\
\hline No & & & & 1 \\
\hline @Tigrie and Kimant; * Significant at P-value less than 0.05; **Significant at P-value less than 0.001 \\
\hline
\end{tabular}

\section{Discussion}

This study determined the proportion of the maternal care service utilization during the perinatal time: prenatal, labor and delivery, and postnatal period among postpartum women in Dabat Demography and Health Survey Site (DHSS), Northwest Ethiopia.

Around eighty percent of the women had at least one antenatal care visit at any health facility. Of which $7 \%$ had it at the health post where there is no laboratory services. This finding was higher than the report of the 2016 Ethiopian Demographic and Health survey (EDHS) (62\%)[12], studies conducted in Abuna Gindeberet District,West Shewa, Ethiopia (53.9\%)[13], and in Hossaina town (69.6\%)[14], Ethiopia and in Nigeria (65.1\%)[15], Zambia (69\%)[16], South Sudan (60.78\%)[17], and Dembecha District (77\%)[10]. This variation might be due to the variation in the reference period they used and variation in residence. The reference period was five years before the date of data collection in the Ethiopian DHS and a study conducted in Nigeria that might predispose for a recall bias. Rural districts were used in the study conducted in West Shewa.

However, this finding was lower than studies conducted in Holeta Town (87.1\%)[18], Addis Ababa(97.6\%) [11], Ethiopia and Kiambu, Kenya (91.73\%)[19], Tanzania (96\%)[20], and India (83\%)[21]. This observed difference might be because of variation in residence. The urban population have a better understanding of the benefit of using maternal health services and have better access to health facilities than the rural ones. This is supported by our data that institutional delivery was eight times higher among urban residents.

Though many women initiated ANC, only less than a third $(31.4 \%, 95 \% \mathrm{Cl}: 29.2,33.7)$ had completed the four recommended focused antenatal care. This finding was consistent with the 2016 Ethiopian demographic and health survey report(32\%)[12], studies conducted in Nekemte town(32.1\%)[22], and Dembecha District (29.8\%)[10] Ethiopia, Zambia (29\%)[16], and Rwanda (30.42\%)[23].

This finding was lower than a study finding conducted in South West Shoa Zone, Ethiopia(45.5\%)[24], a national-level study (36.78\%) and its disaggregated analysis report for Addis Ababa (89.33\%), Dire Dawa (65.15\%) and Tigray Region (55.83\%)[25] regions, a study conducted in Debre Tabor Town(35.3\%)[26], 
Holeta town (61.6\%)[18], Addis Ababa (53.4\%)[11], Hossaina town (38.7\%)[27], Ethiopia, Tanzania $(58.2 \%)[20]$, and Nigeria (56.2\%)[15]. Majority of the study areas for the above articles are urban that urban population had better awareness of the relevance of using maternal health services. In these studies, majority of the study participants had attended a formal class than participants in this study. For example, the proportion of no formal education in this study was $75.15 \%$, while it was only $11.1 \%, 15.4 \%$, $32 \%$, and $33.4 \%$ in studies conducted in Hossaina town, Addis Ababa, Holeta town, Ethiopia and Nigeria respectively $[11,15,18,27]$. Additionally, the study conducted in Addis Ababa is a facility-based study that the participants were those who came for child immunization. These women might have better health care seeking behavior. A study conducted in Nigeria used a five year reference period prior to the date of data collection that might be prone for recall bias.

Nearly half, $49.2 \%(95 \% \mathrm{Cl}=46.7,51.8)$ of the women gave birth in health institutional/facility. This study finding was higher than the 2016 Ethiopian DHS finding (26\%)[12], studies conducted in Abuna Gindeberet District, West Shewa(14.4\%)[13], Dembecha District(31.4\%)[10], Sekela district(12.1\%)[28], Dangila district(18.4\%)[29], Afar (22.4\%)[30], Dodota district, Oromia region(18.2\%)[31], Southern Ethiopia(38\%)[32], Munisa district, Arsi zone, Southeast Ethiopia(12.3\%)[9], Rwanda(39.5\%)[23], and Uganda $45.4 \%[33]$. The discrepancy might be due to difference in socio-cultural beliefs and exposure to information since the current study area is under research center that the community might have better awareness than others. The difference with Rwanda might be due to the difference in the study period that it was about five year ahead of the current study. The same is true for the study conducted in the Abuna Gindeberet District. There might be individual, and service accessibility related difference to contribute to the observed difference.

In the contrary, institutional delivery in the current study was lower than studies conducted in Holeta town (61.6\%)[18], a national level study (56\%)[34], Debremarkos town (57.1\%)[35],Addis Ababa (96.2\%)[11], Hossaina town (64\%)[27] Ethiopia. The possible reason for the existed difference in institutional delivery between this study and a study conducted in Holeta town, Addis Ababa city, and Hossaina town might be due to a high proportion of participants had used ANC in Holeta town which subsequently got counseling on birth preparedness (facility delivery) and complication readiness, and on the uptake of postnatal care. Additionally, variation in socio-demographic characteristics like residency and education and its subsequent women decision making power and health care-seeking behavior might contribute to the observed difference in institutional delivery. Additional reason for the difference with a national level study done by Fekadu et al was due to difference in the study participants that the other study includes only women who had attended ANC for four or more visits that they had good health care-seeking behavior.

Compared to studies conducted abroad like India (68\%)[21], Zambia (57\%)[16], and Tanzania (76.8\%)[20], Jaipur district of Rajasthan(99.56\%)[36], Guena (52\%)[37], and in the study conducted in Biharamulo District, Tanzania(56\%)[38], the institutional delivery in the current study was found low. This might be due to socio-economic and cultural difference. 
About half, $822(50.6 \%, 95 \% \mathrm{Cl}: 48.2,52.9)$ of postpartum women participated in this study had at least one postnatal care (PNC) visit at health facilities. This finding is consistent with a study finding in Hossaina town (51.4\%)[27]. However, this finding was higher than a pooled estimate report of metaanalyses in Ethiopia (31.3\%)[39] and studies conducted in different parts of Ethiopia like in Debremarkos town (33.5\%)[35], Abuna Gindeberet District, West Shewa(31.7\%)[13], Dembecha (31.4\%)[10], Halaba Kulito town, southern Ethiopia(47.9\%)[40], South Sudan (11.4\%)[17], Kenya (45.1\%)[19], Rwanda (12.8\%) [23], Tanzania (43.5\%)[20], and India (26.3\%)[21]. Attending ANC and/or institutional delivery have a great effect on the uptake postnatal care (PNC) because ANC is a gateway for institutional delivery as well as for PNC service utilization. The low prevalence of ANC utilization in studies conducted in Debre Markos town, Abuna Gindeberet District, West Shewa Ethiopia, south Sudan, and Rwanda might take part for poor PNC utilization in these studies than the current study. In India, the respondents were rural residents. This might be the reason for the variation in using PNC between this and current study. The socio-cultural variation and accessibility of the services across regions of Ethiopia and countries might contribute the existed difference between the current and other studies. However, PNC utilization in this study was lower than a study conducted in Addis Ababa (65.6\%)[11], Debretabor town(57.5\%)[41], Debre Birhan Town(83.3\%)[42]. This is because they these studies were conducted entirely in urban where majority of participants were educated, relatively empowered, have better awareness and good health care seeking behavior.

Bivariable and multivariable logistic regression analyses were done to identify factors associated with institutional delivery. Residence, respondents' educational status, religion, number of TT vaccination taken during pregnancy for indexed child, and ANC utilization at recommended place had association with institutional delivery.

Institutional delivery was eight times higher among postpartum women who were living in urban than living in rural. This is because urban women had better awareness on the benefits of institutional delivery, better decision making power on health care services utilization than rural ones. Women's decisionmaking power plays a significant role in determining uptake of maternal health services[43]. Additionally, physical accessibility of health facility is better in urban than rural. The same finding was also observed in a national level study conducted in Ethiopia[44, 45], lay Gayint district, Ethiopia[46], and studies conducted in Bangladish [47, 48].

Postpartum women who were secondary school and above in their educational status were five times more likely to give birth at health facility as compared to those who had no formal class. This is due to the difference in awareness on the potential risks of giving birth at home. Furthermore, their autonomy to decide on place of delivery is better in educated women than non-educated ones. A similar finding was also observed in different studies conducted in Ethiopia[44, 45] and Bangladish [48].

The odds of giving birth at health facility was two times higher in Muslim religion followers than Orthodox Christian. This might be due to the reason that the majority of Muslim religion followers live in urban where there is relatively better access to health facility and high chance to exposure to mass 
media. However, this finding contradicts the study finding in Bangladish where institutional delivery was found in non-Muslims[47]. Postpartum women who took two doses of TT vaccination during pregnancy for the indexed child were $54 \%$ higher to give birth at health facility than those who did not take the vaccination. If women took the recommended dose of TT vaccination, their health care seeking behavior will become good. Women's good health care seeking behavior can affect them for institutional delivery[48]. Similarly, women who used ANC at recommended place were three times higher to deliver at health facility than those who had no ANC follow up. This is mainly due to the counseling or advice given by the health professionals during antenatal care service utilization about birth preparedness and complication readiness. This counseling can improve mothers' awareness and can change mothers' behavior regarding obstetrical services. Hence, ANC is a gateway for the continuum of obstetric care. Similar findings are observed in studies conducted in Ethiopia[44-46], Bangladish[47, 48], Tanzania[49], and in Myanmar[50].

\section{Conclusions}

Maternal health services utilization is highly important in reducing maternal and fetal/infant mortality and morbidities. We found that nearly three-fourth of pregnant women had at least one ANC visit. Utilization of all the recommended focused antenatal care follow up was low. Similarly, though most maternal death happens during labor and delivery, and postnatal period, institutional delivery/skilled birth attendants, and postnatal care utilization were low. Socio-demographic and use of antenatal and its related services are factors associated with institutional delivery. Promoting women for ANC and awareness creation activities giving a high emphasis for rural and uneducated women are important to improve institutional delivery.

\section{Declarations}

\section{Ethics Approval and consent to participate}

Ethical approval was obtained from the ethical institutional review board (IRB) of the University of Gondar with a reference number: O/V/P/RCS/05/473/2015. Permission was also obtained from woreda health offices. Before data collection, adequate information about the purpose of the study, the privacy and confidentiality nature of the study, and their right not to participate or to withdraw at any time from the study have been given to the study participants. Informed consent was obtained from each participant. The data were collected anonymously. The collected data are not accessed to the third party other than the investigators. All the methods employed in the manuscript were performed in accordance with the relevant guideline and regulations and confirmed by the IRB.

\section{Consent for Publication}

Not applicable 


\section{Availability of data and materials:}

All the required data are found in the main manuscript.

\section{Competing interest}

Authors declared that we have no any conflict of interest.

\section{Funding}

This finding is a baseline survey of a longitudinal data on maternal, Neonatal and Child Health (MNCH) which was financially supported by University of Gondar under a grant O/V/P/RCS/05/473/2015. This financial support was to do the study but not for publication.

\section{Authors' Contributions}

AGW led the conception and design of the study, AAG, AGW, DTB, NBT, MHG, HYY, EAC, BAD, AT, AKB, BAY and $G A B$ contributed in the conception and design of the study and supervision of data collection. $A A G^{1}$ and $A M L^{4}$ performed the statistical analysis and interpretation of the result. All the authors contributed in the revision of the manuscript, read and approved the final manuscript.

\section{Acknowledgments}

The authors are would like to acknowledge University of Gondar for its financial support for this research project. We would also like to thank the study participants, data collectors, and supervisors for their contribution in this study.

\section{References}

1. Olopade, F., and, and T. Lawoyin, Maternal mortality in a Nigerian maternity hospital. African Journal of Biomedical Research, 2010. 11: p. 267-273.

2. Adewemimo, A., et al., Utilisation of skilled birth attendance in Northern Nigeria: A cross-sectional survey. Midwifery, 2014. 30: p. e7-e13.

3. World Health Organization, Maternal Mortality: Fact sheets. 2019.

4. Yakoob, M., et al., The effect of providing skilled birth attendance and emergency obstetric care in preventing still births. BMC Public Health 2011. 1(8).

5. Wolelie, A., et al., Institutional delivery service utilization and associated factors in Banja District, Awie Zone, Amhara Regional Sate, Ethiopia. Open Journal of Epidemiology, 2014. 4: p. 30-35. 
6. Ahmed, A., Maternal Mortality Trend in Ethiopia. Ethiop J Health Dev, 2010. 24(1): p. 117-120.

7. World Health Organization, Postnatal Care for Mothers and Newborns: Highlights from the World Health Organization 2013 Guidelines. 2015.

8. World Health Organization, WHO recommendations on antenatal care for a positive pregnancy experience. 2016.

9. Amano A., Abebaw Gebeyehu A., and Birhanu Z., Institutional delivery service utilization in Munisa Woreda, South East Ethiopia: a community based crosssectionalstudy. BMC Pregnancy and Childbirth 2012. 12(105).

10. Hordofa M.A., et al., Postnatal care service utilization and associated factors among women in Dembecha District, Northwest Ethiopia Science Journal of Public Health, 2015. 3(5): p. 686-692.

11. Berhanu S., Asefa Y., and Giru B. W., Prevalence of postnatal care utilization and associated factors among women who gave birth and attending immunization Clinic in Selected Government Health Centers in Addis Ababa, Ethiopia. Journal of Health, Medicine and Nursing, 2016. 26: p. 94-108.

12. Central Statistical Agency (CSA) [Ethiopia] and ICF., Ethiopia Demographic and Health Survey 2016. Addis Ababa, Ethiopia, and Rockville, Maryland, USA: CSA and ICF. 2016.

13. Darega B., et al., Institutional delivery and postnatal care services utilizations in Abuna Gindeberet District, West Shewa, Oromiya Region, Central Ethiopia: A Community-based cross sectional study. Pregnancy and Childbirth, 2016. 16: p. 149.

14. Abosse Z., et al., FACTORS INFLUENCING ANTENATAL CARE SERVICE UTILIZATION IN HADIYA ZONE. Ethiop J Health S, 2010. 20(2).

15. Adeniyi Francis Fagbamigbe \& and Erhabor Sunday Idemudia, Wealth and antenatal care utilization in Nigeria: Policy implications. Health Care for Women International, 2017. 38(1): p. 17-37.

16. Jacobs C., et al., Predictors of antenatal care, skilled birth attendance, and postnatal care utilization among the remote and poorest rural communities of Zambia: a multilevel analysis Public Health Frontiers 2017. 5.

17. Izudi J., G. D. Akwang G. D., and Amongin D., Early postnatal care use by postpartum mothers in Mundri East County, South Sudan,. BMC Health Services Research, 2017. 17: p. 442, 2017.

18. Birmeta K., Dibaba Y., and Woldeyohannes D., Determinants of maternal health care utilization in Holeta town, central Ethiopia.. BMC Health Services Research, 2013. 13: p. 256.

19. Njoka N., et al., Appreciating the essence of post natal care services from mothers' perspective in Kiambu, Kenya. British Journal of Medicine and Medical Research, 2017. 20(3): p. 1-13.

20. Orwa J., et al., Maternal healthcare services use in Mwanza Region, Tanzania: a cross-sectional baseline survey. BMC Pregnancy and Childbirth, 2019. 19: p. 474.

21. Singh R., et al., Utilization of maternal health services and its determinants: a cross-sectional study among women in rural Uttar Pradesh, India. Journal of Health, Population and Nutrition, 2019. 38 : p. 13. 
22. Woyessa A. H and A.T. H, Assessment of focused antenatal care utilization and associated factors in Western Oromia, Nekemte, Ethiopia. BMC Research Notes, 2019. 12: p. 277.

23. Rwabufigiri B. N., et al., Factors associated with postnatal care utilisation in Rwanda: A secondary analysis of 2010 Demographic and Health Survey data. BMC Pregnancy and Childbirth, 2016. 16: p. 122.

24. Wilunda C. et al., Determinants of utilisation of antenatal care and skilled birth attendant at delivery in South West Shoa Zone, Ethiopia: a cross sectional study. Reproductive Health, 2015 12: p. 74.

25. Tegegne T. K., et al., Antenatal care use in Ethiopia: a spatial and multilevel analysis. BMC Pregnancy and Childbirth 2019. 19: p. 399.

26. Ayalew T. W. and Nigatu A. M., Focused antenatal care utilization and associated factors in Debre Tabor Town, northwest Ethiopia, 2017. BMC Research Notes, 2018 11: p. 819.

27. Dutamo Z, Assefa N, and E. G., Maternal health care use among married women in Hossaina, Ethiopia,. BMC Health Services Research, 2015. 15: p. 365.

28. Teferra, A.S., et al., Institutional delivery service utilization and associated factors among mothers who gave birth in the last 12 months in Sekela District,North West of Ethiopia: A community - based cross sectional study. BMC Pregnancy and Childbirth 2012. 12(74).

29. Demilew, Y., G. Gebregergs, and A. Negusie, Factors associated with institutional delivery in Dangila District, North West Ethiopia: a cross-sectional study. Afri Health Sci., 2016. 16(1): p. 10-17.

30. Mohammed, M.J., et al., Institutional delivery service utilization and associated factors among mothers in Afambo district, Afar, Ethiopia - 2016. Community- based cross sectional study. Medico Research chronicles, 2017. 4(4): p. 363-379.

31. Fikre, A.A., and, and M. Demissie, Prevalence of institutional delivery and associated factors in Dodota Woreda (district), Oromia regional state, Ethiopia. Reproductive Health 2012. 9(33).

32. Arba MA, Darebo TD, and Koyira MM, Institutional Delivery Service Utilization among Women from Rural Districts of Wolaita and Dawro Zones, Southern Ethiopia; a Community Based Cross-Sectional Study. PLoS ONE, 2016. 11(3): p. e0151082.

33. Anyait, A., et al., Predictors for health facility delivery in Busia district of Uganda: a cross sectional study. BMC Pregnancy and Childbirth, 2012. 12(132).

34. Fekadu G. A., Ambaw F., and Kidanie S. A., Facility delivery and postnatal care services use among mothers who attended four or more antenatal care visits in Ethiopia: further analysis of the 2016 demographic and health survey. BMC Pregnancy and Childbirth, 2019. 19: p. 64.

35. Limenih M. A., Endale Z. M., and Dachew B. A., Postnatal Care Service Utilization and Associated Factors among Women Who Gave Birth in the Last 12 Months prior to the Study in Debre Markos Town, Northwestern Ethiopia: A Community-Based Cross-Sectional Study. International Journal of Reproductive Medicine, 2016. Volume 2016: p. 7 pages.

36. Kusum, L.G., et al., Factors Associated with Antenatal Care Services Utilization and Institutional deliveries. IOSR. Journal of Dental and Medical Sciences (IOSR-JDMS), 2014. 13(4). 
37. Ellen, B.R., et al., Rethinking How to Promote Maternity Care-Seeking: Factors Associated With Institutional Delivery in Guinea. 35, 2014. 7-9: p. 878-95.

38. Alkmejmk, Prevalence and predictors of institutional delivery among pregnant mothers in Biharamulo district, Tanzania: a crosssectional study. The Pan African Medical Journal 2015.

39. Geremew A. B., Boke M. M., and Yismaw A. E., The Effect of Antenatal Care Service Utilization on Postnatal Care Service Utilization: A Systematic Review and Meta-analysis Study. Hindawi Journal of Pregnancy, 2020. Volume 2020: p. 7 Pages.

40. Abebo T. A. and Tesfaye D. J., Postnatal care utilization and associated factors among women of reproductive age Group in Halaba Kulito Town, Southern Ethiopia. Archives of Public Health 2018. 76: p. 9.

41. Wudineh K. G., et al., Postnatal care service utilization and associated factors among women who gave birth in Debretabour town, North West Ethiopia: a community-based cross-sectional study. BMC Pregnancy and Childbirth 2018. 18: p. 508.

42. Angore B. N., Tufa E. G., and Bisetegen F. S., Determinants of postnatal care utilization in urban community among women in Debre Birhan Town, Northern Shewa, Ethiopia. Journal of Health, Population and Nutrition 2018. 37: p. 10.

43. Tiruneh F.N., Chuang K.Y., and Chuang Y.C., Women's autonomy and maternal healthcare service utilization in Ethiopia. BMC Health Services Research, 2017. 17: p. 718.

44. Berelie, Y., et al., Determinants of institutional delivery service utilization in Ethiopia: a population based cross sectional study. BMC Public Health, 2020. 20(1).

45. Mekonnen Z. A., et al., Multilevel analysis of individual and community level factors associated with institutional delivery in Ethiopia. BMC Res Notes 2015. 8: p. 376.

46. Nigatu A. M and Gelaye K. A, Factors associated with the preference of institutional delivery after antenatal care attendance in Northwest Ethiopia. BMC Health Services Research, 2019. 19: p. 810.

47. Kamal, S.M.M., C.H. Hassan, and G.M. Alam, Determinants of Institutional Delivery Among Women in Bangladesh. Asia Pacific Journal of Public Health, 2013. 27(2).

48. Yaya S, Bishwajit G, and Ekholuenetale M, Factors associated with the utilization of institutional delivery services in Bangladesh. PLoS ONE 2017. 12(2): p. e0171573.

49. Bishanga DR, et al., Factors associated with institutional delivery: Findings from a cross-sectional study in Mara and Kagera regions in Tanzania PLoS ONE, 2018. 13(12): p. e0209672.

50. Aung T, et al., DETERMINANTS ON THE UTILIZATION OF INSTITUTIONAL DELIVERY IN RURAL AREAS OF MYAING TOWNSHIP, MAGWAY REGION, MYANMAR. JUMMEC, 2020. 23.

\section{Figures}




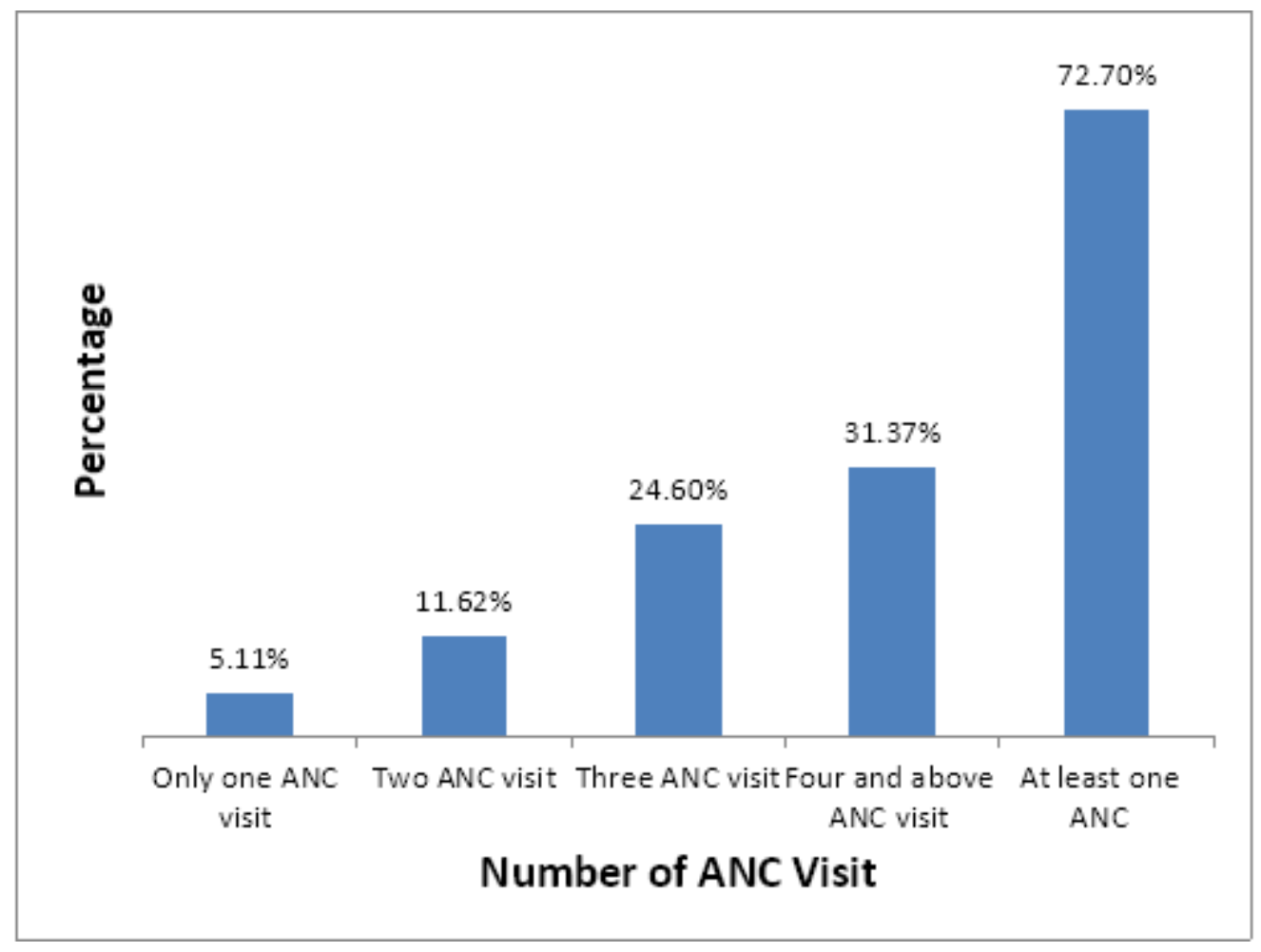

\section{Figure 1}

Number of ANC visit at health facilities where there was laboratory services among postpartum women at Dabat Demographic and Health Survey site, 2016

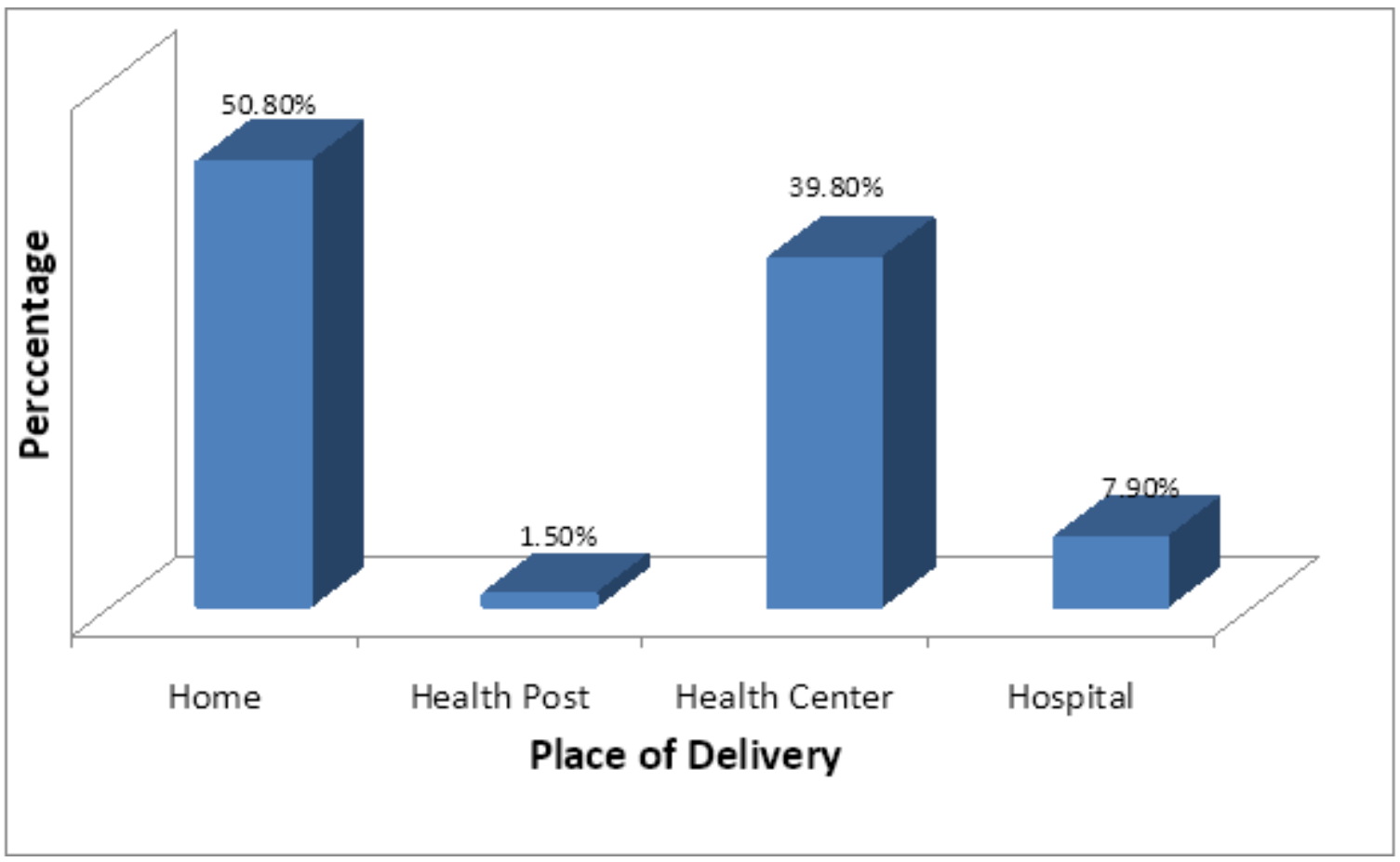

Figure 2

Place of delivery among postpartum women at Dabat Demographic and Health Survey site, 2016 


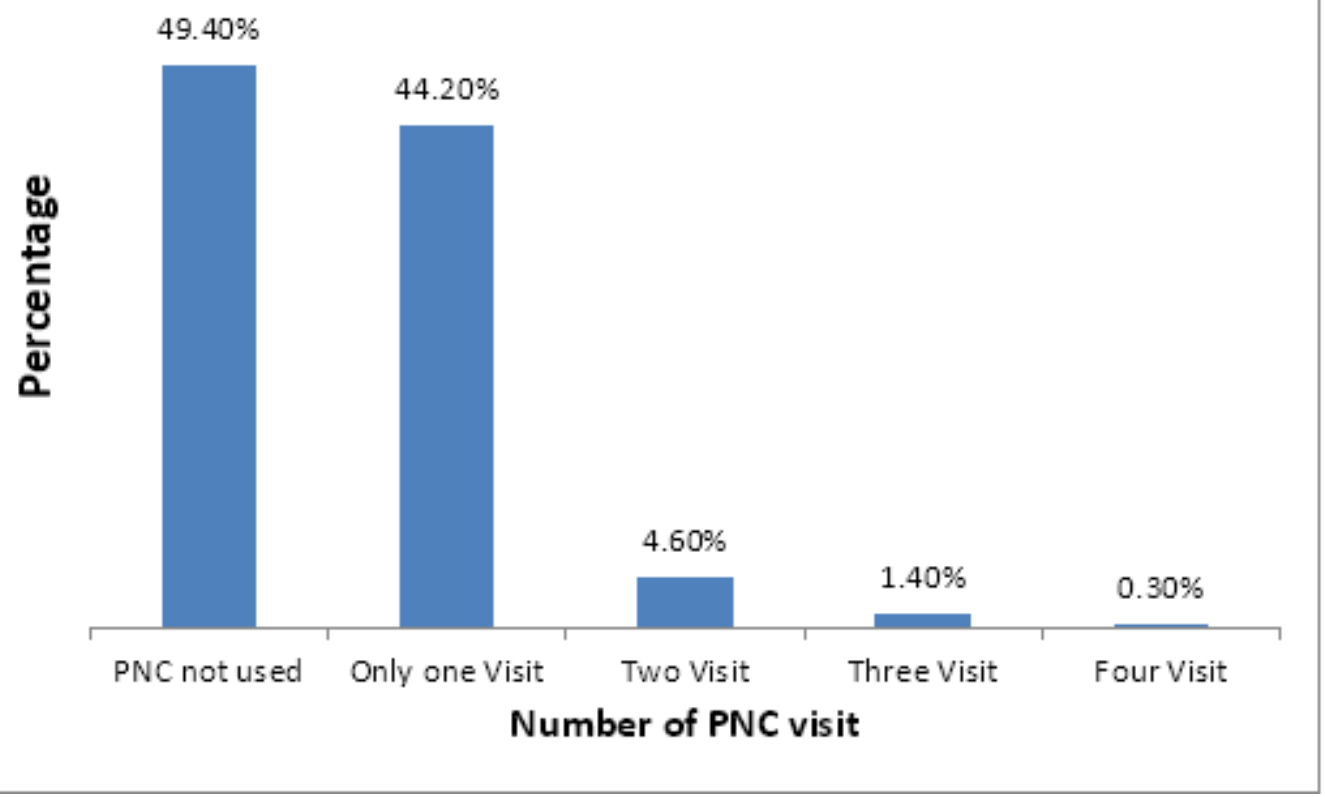

Figure 3

Number of PNC visit attended by postpartum women at Dabat Demographic and Health Survey site, 2016 